\title{
Robotized Spraying of Prefabricated Panels
}

A robotized manufacturing cell of pre-fabricated GRC (Glass Reinforced Cement) panels for construction industry has been developed by DISAM for the Spanish construction company Dragados, S.A. The main contribution of the developed system is the automatic programming and control of the whole plan. The architect's 3D-drawing of the building facade done on a $\mathrm{CAD}$ system serves as input. From the CAD design, the optimum facade to panels partition is obtained. In order to manufacture each panel, automatic task and path planning are performed for the equipment present in the manufacturing cell: spraying robot, PLCs, control computer, etc.

A utomation in the construction industry is still well below the automation levels of other industries, although an increasing effort has been made in recent years. Applying automation in this important industrial sector is very difficult because of the non-repetitive processes, the low level of standardization and the highly non-structured on-site environments.

Construction activities can be divided into two main groups: off-site and on-site. On-site processes form what is considered typical construction work, i.e., building. These activities are the most difficult to automate, mainly because of the highly complex and variable environments in which they take place. Despite this difficulty some robots have been developed for this purpose [1], [2]. Off-site construction processes are more suitable to be robotized, since the work takes place in a structured environment and process variables are under control.

A common off-site process is the manufacturing of prefabricated panels which are later assembled on-site. In

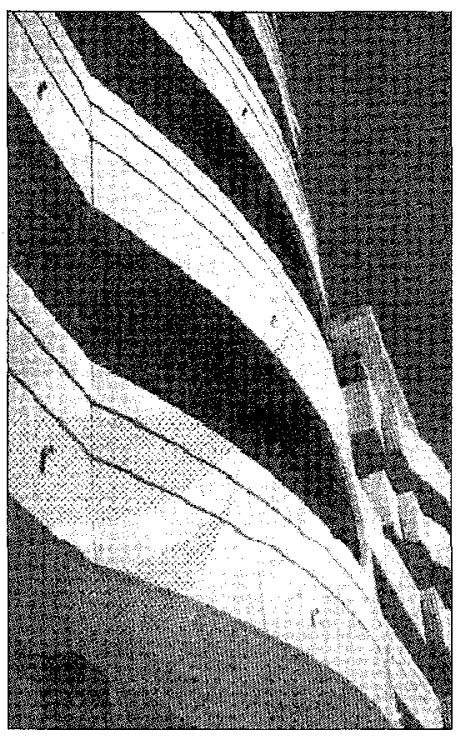

Figure 1. Typical building facade using GRC panels. recent years one important material used in this kind of industry has been Glass Reinforced Cement (GRC). GRC technology is 30 years old, and thanks to its flexibility has become very popular. GRC material is prepared by mixing cement with small cut glass fiber strips, achieving enough flextraction strength while maintaining light weight $\left(40-60 \mathrm{~kg} / \mathrm{m}^{2}\right.$ in comparison with conventional concrete panels 210-230 $\left.\mathrm{kg} / \mathrm{m}^{2}\right)$. This allows the manufacture of very large panels $(6 \times 3 \mathrm{~m})$ of any $3 \mathrm{D}$ geometry with the dual advantage of easy transportation and easy assembly on site.

The Spanish construction company, Dragados S.A. (DyC), has been using manually manufactured GRC panels mainly as facade units for a long time (Fig. 1). The excellent finished quality of the external parts of GRC panels enables them to be applied in a great variety of circumstances.

Adequate quality is a limit-
*Department of Automatica (DISAM), Universidad Politécnica de Madrid, ciJose Gutierrez Abascal, 2, 28006 Madrid, Spain. "Department of Engineering, Lniversidad Carlos III de Madrid, c/Butarque, 15, 28911 Leganés (Madrid), Spain. ing factor in the production of GRC panels using this manual method. Therefore a project to develop a robotized manufacturing cell of prefab- 
ricated GRC panels was launched in 1991. The automation cell, now installed in a factory near Madrid, has been developed by the Polytechnic University of Madrid (DISAM) for DyC with the financial support of the Spanish Ministry of Industry and Energy.

\section{PROBLEM STATEMENT}

Manual manufacturing of GRC panels uses a conventional concentric spraying gun equipped with glass fiber cutting razors. The mortar and the glass fiber strips are projected on a panel mold in two different but simultaneous shots which are mixed in the air and form a spraying cone (Fig. 2). The required final thickness $(1-1.5 \mathrm{~cm})$ of the panel is obtained by progressive spraying into the mold of several $0.2-0.5 \mathrm{~cm}$ layers. After each layer is sprayed, manual compacting by roller

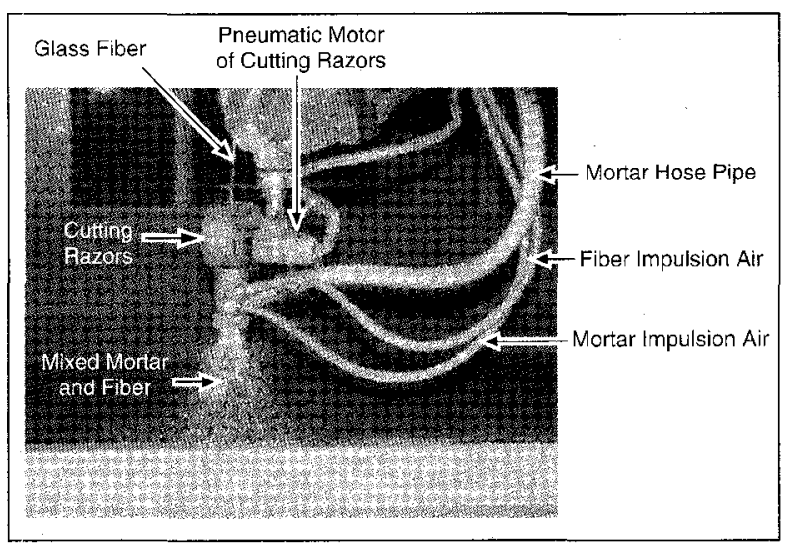

Figure 2. Concentric spraying gun.

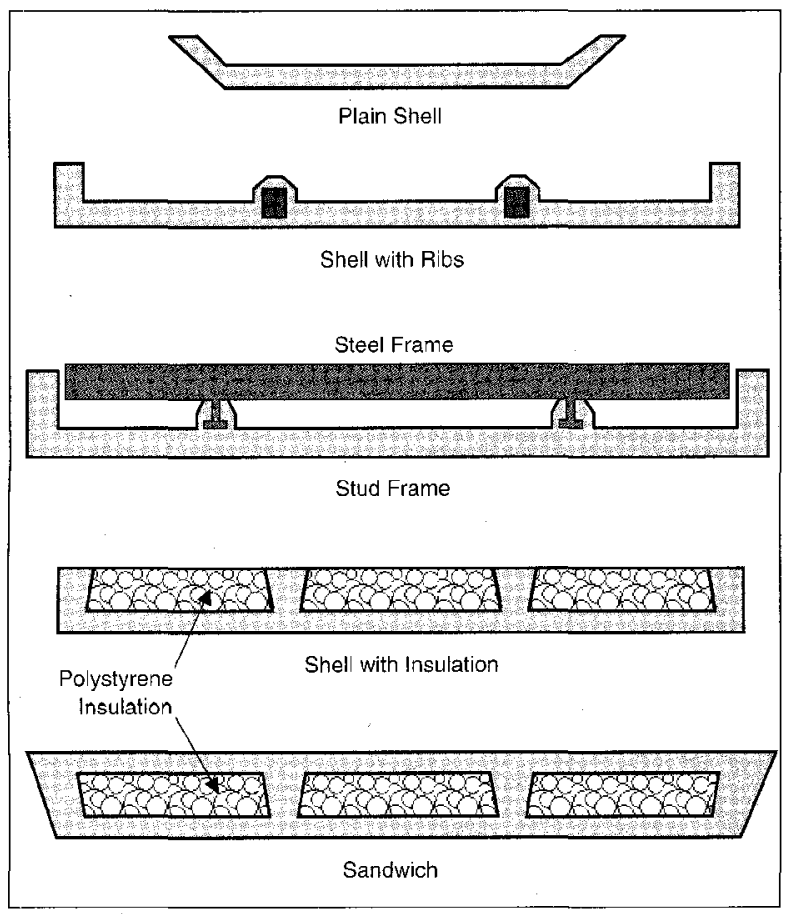

Figure 3. Different types of GRC panels. is necessary. Commonly the spraying process is done by one operator while at the same time two or three others are compacting. Cycle time for manual manufacturing varies with panel type and size from 15 to $30 \mathrm{~min}$, without taking into account a set of auxiliary operations performed before and after projection and compacting.

A major requirement is to achieve great uniformity during the spraying process. In manual production this feature depends on the worker's ability and experience in positioning, orientating, and moving the spraying gun at constant speed.

Working conditions and environment impact are other important factors. Workers are faced with a very dirty and contaminated environment, which not only affects their performance, but presents a high risk to their health.

Another aspect is the fact that the 3D geometry of panels changes very frequently, requiring a high degree of system flexibility. These variations clepend on the architect's design and the building for which they are destined. In the Caracola DyC factory the average series for a given panel in the last seventeen years has been five units. Even if small differences between panels are disregarded, series do not exceed fifty units and only in very rare cases equal a hundred units. This diversity of geometries is inevitable in facade oriented panels.

Panels differ according to the type and number of layers to be sprayed. The first layer, which forms the external surface of the resulting panel, is common to all of them. It consists of with mortar without fiber up to a total thickness of $2 \mathrm{~mm}$. Depending on the remaining layers, there are five distinct types of panels (Fig. 3):

- Plain shell: two more layers of mortar and fiber up to a total thickness of $10 \mathrm{~mm}$.

- Shell with ribs: same as plain shell but with stiffening ribs.

- Stud frame: same as plain shell but with a steel frame.

- Shell with insulation: same as plain shell but with insulation sheets.

- Sandwich: same as plain shell with insulation with an additional GRC top layer.

\section{OBJECTIVE}

From the preceding section it is clear that some kind of automation which improves flexibility and quality is desirable. Therefore the objective of the automation project has been the design of a robotized system in order to replace manual processes as appropriate while improving labor conditions, reducing wasted material, increasing product quality and uniformity, and reducing labor requirements (Fig. 4). The production of GRC panels includes several stages, of which spraying and compacting are the most critical. Therefore, automation efforts have focused on these two [3].

Based on the experience obtained through the years of manual production the system is designed to be flexible enough to cope with small batch size production of different panels, integrating CAD and CAM. A great effort has been made to develop an integrated flexible low-cost system to be used on a range of similar applications, such as gluing, sealing, and cleaning.

A highly flexible production unit which is capable of manufacturing a large variety of small series under quasi-real time request is now crucial for most companies. This flexibility can be achieved in the manufacturing environment with the use of 

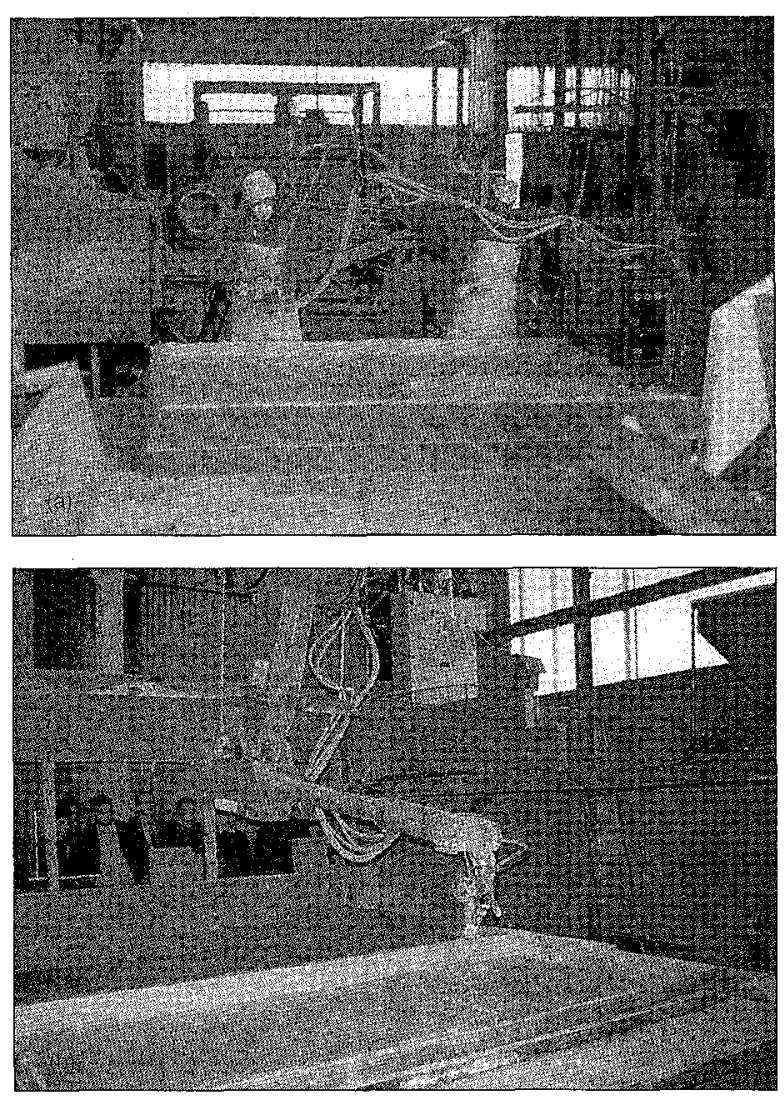

Figure 4. a) Traditional manual process. b) New developed robotized process. with spraying/compacting being a particular case.

\section{SYSTEM ARCHITECTURE}

The manufacture of a GRC panel goes through several stages: 1) mold preparation (including the placement of clamps for later assembly on site); 2) spraying/compacting; 3) hardening; 4) panel extraction from the mold; and 5) curing. The mold is currently manually constructed in wood; however, with the appearance of new materials, automation of this stage could also be considered [7]. As spraying/compacting is the most critical stage and moreover is very labor intensive, automation efforts have focused on it. The rest of the processes maintain their conventional procedures of operation, with the addition of two new stages: automatic feeding of empty molds to the spraying/compacting cell and removal of finished molds, both implemented through the use of roller conveyors.

As mentioned above, the objective was the automation of both the spraying and compacting processes, but initial experiments with the spraying cell demonstrated that the quality of the spraying was so good that intermediate compacting stages could be eliminated. Acknowledgment of this fact lead to only improving the spraying cell.

Fig. 5 shows a scheme of the cell. We now briefly describe the equipment involved in the whole manufacturing process.

- Spraying robot: An ABB IRB 3200, 6 DOF articulated commercial robot, placed upside down in the center of the cell. It is capable of being controlled in real-time from an external computer via a serial Computer Link.

- Spraying gun: A concentric spraying gun attached to the tip of the robot with a power of up to $28 \mathrm{~kg} / \mathrm{min}$ (pressure 3 times greater than the maximum possible in manual spraying). It cuts the glass fiber in small strips and airmixes them with the cement mortar. Mortar parameters
Flexible Manufacturing Systems (FMS) under Computer Integrated Manufacturing (CIM) [4]. This concept has been recently adapted to the construction industry as Computer Integrated Construction (CIC) [5]. The development of an FMS for CIC must consider the inherent barriers common to these kinds of systems: 1) low level of reuse of software and/or hardware; 2) medium level robustness of the developed algorithms under new manufacturing conditions; and especially 3) the difficulties of the know-how transfer between the developing institution and the recipient. Hence in order to be efficient it is very important to design an FMS that can be programmed for a family of applications. This is what has been done in the development of the GRC spraying/compacting cell [6]. The intention from the very beginning was to develop an FMS for a family of different applications related to $3 \mathrm{D}$ surface treatment: spraying, painting, cleaning, sealing, etc.,

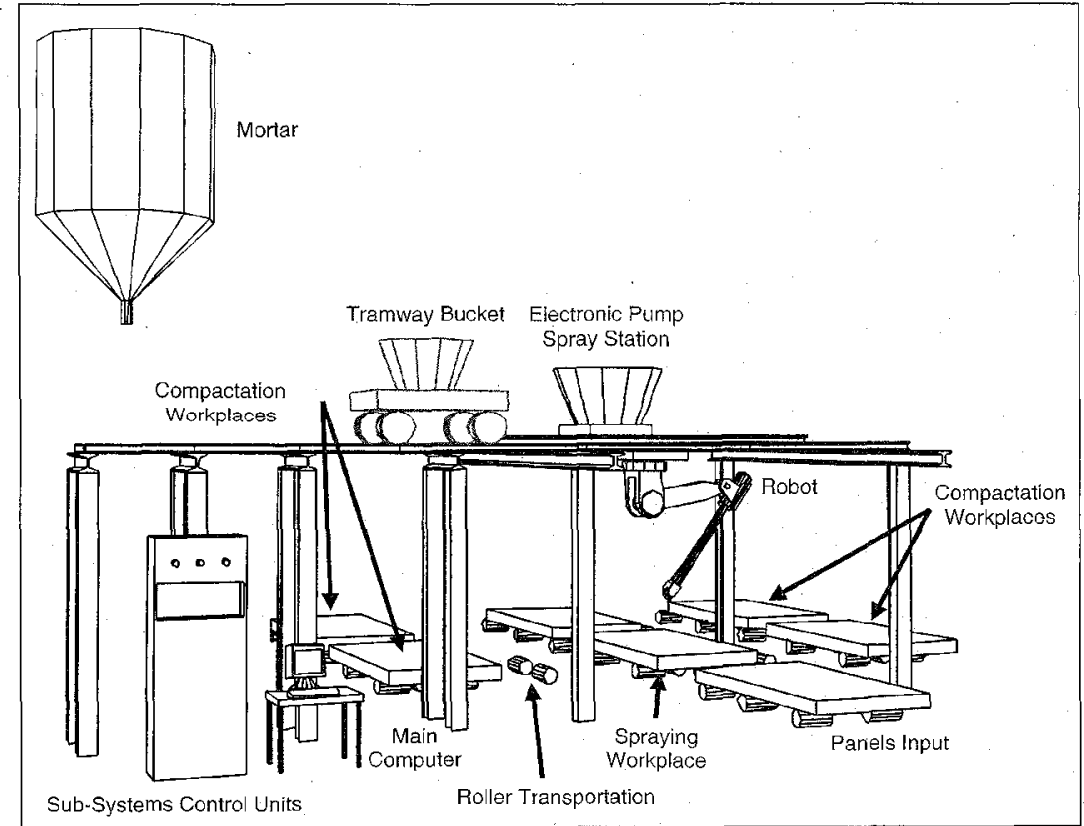

Figure 5. Scheme of the cell. 
are controlled by an electronic pump.

- On-line main computer: An industrial PC connected to: 1) the robot Computer Link; 2) the field-bus PLCs network which controls several components of the cell (electronic pump, roller conveyors and hopper and mixer); and 3) the off-line computer. The on-line computer monitors the status of all the equipment, presenting the information through a man-machine interface. Moreover, it schedules the parts to be manufactured on each working day, based on the types of mix, size, etc.

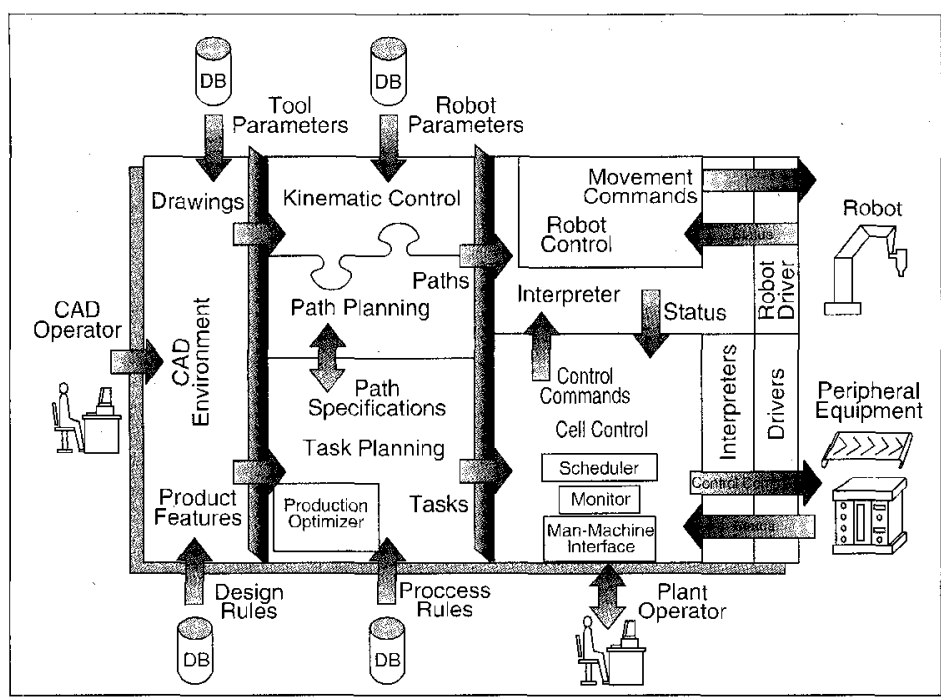

Figure 6. Scheme of the control system.

- Off-line computer: A PC with a commercial CAD package (AUTOCAD v12 + AME v2.0), located in the design office. This is where the CAD process is performed, followed by the different steps that lead to the generation of a set of control commands and procedures for cell equipment.

- Programmable Logic Computers (PLCS): Three Siemens PLCs, connected to the on-line main computer via network. These control, respectively, the electronic pump, the hopper and mixer and the roller conveyors.

- Roller conveyors: 3-meter wide roller conveyors, used to introduce the molds in the spraying cell and to take them out after completion. Since the maximum reach of the robot is approximately a square area of $3 \times 3 \mathrm{~m}$, panels more than 3 meters long must be placed when sprayed in two fixed different positions with the roller conveyors.

Fig. 6 presents the control system structure of the developed GRC manufacturing system. Although the concepl is general, for better understanding the explanation will address the specific application of manufacturing prefabricated panels. One of the more important aspects that characterizes the system is the integration of CAD with CAM, which is indispensable for small batch production of different panels. Molds are designed on a commercial CAD environment with access, through a special interface, to information about the manufacturing tool (spraying gun) and parameters and design rules of the product. The information generated by the CAD envi- ronment concerns $3 \mathrm{D}$ drawings and product features, i.e., number and thickness of layers, etc. This raw information is processed through an off-line module, similar to the computed distributed system used in [9]. The module is formed by three interrelated sub-modules: robots kinematics control, path planning, and task planning. Fach sub-module generates commands (paths, tasks, etc.) for the on-line equipment in the manufacturing cell: robot, computers, PLCs, etc.

The system has been designed in accordance with the flexible manufacturing concept. Its main advantages are direct integration of the $\mathrm{CAD} / \mathrm{CAM}$ environment, rapid design-production cycle and low-cost hardware and software structure.

A commercial 6 DOF robot was selected as the spraying machine. Since manual programming of the robot was impossible due to the complexity and the great number of different panels, off-line programming was adopted. For this reason, real-time communication with the robot through a computer link has been a key factor in robol selection.

\section{CAD ENVIRONMENT}

One advantage of this system is the integration of CAD with CAM, and especially automatic robot path-planning directly from 3D CAD drawings. First, the $\mathrm{CAD}$ operator makes a detailed drawing of the desired building facade. To facilitate the design, a set of software utilities is included in the menu bar of AUTOCAD. These utilities are dialogue boxes to guide the design process in an easy way. Once the facade has been drawn under solid modeling through AME, the automatic facade partitioning into elementary panels is performed (Fig. 7). For this purpose it is necessary to consider process specifications, i.e., the maximum size of panels to be manufactured, windows and doors sectioning, etc. Finally, molds are generated from the elementary panels.

For each panel, the operator must specify (also with the help of guided menus) various general process and tool parameters that normally remain fixed for several panels. These parameters include: spraying cone angle, rated spraying flow, number and type of layers (bottom or side, thickness, material), type and position of insulators and clamps, etc. Finally, the operator can launch first the automatic generation of layers in the CAD environment and then the robot path planning procedure.

\section{SPRAYING RULES}

The path planning process depends mainly on some spraying rules that were obtained from a careful study of manual spraying, with an empirical parametrization of the spraying cone [10], and later adapted to the particularities of robot spraying. They are:

- Spraying must be performed perpendicular to the surface whenever possible.

- The surface to be sprayed is divided into parallel spraying paths. Path width is adjusted modifying the spraying distance to obtain an integer number. The spraying distance $\mathrm{D}$ is obtained from: 

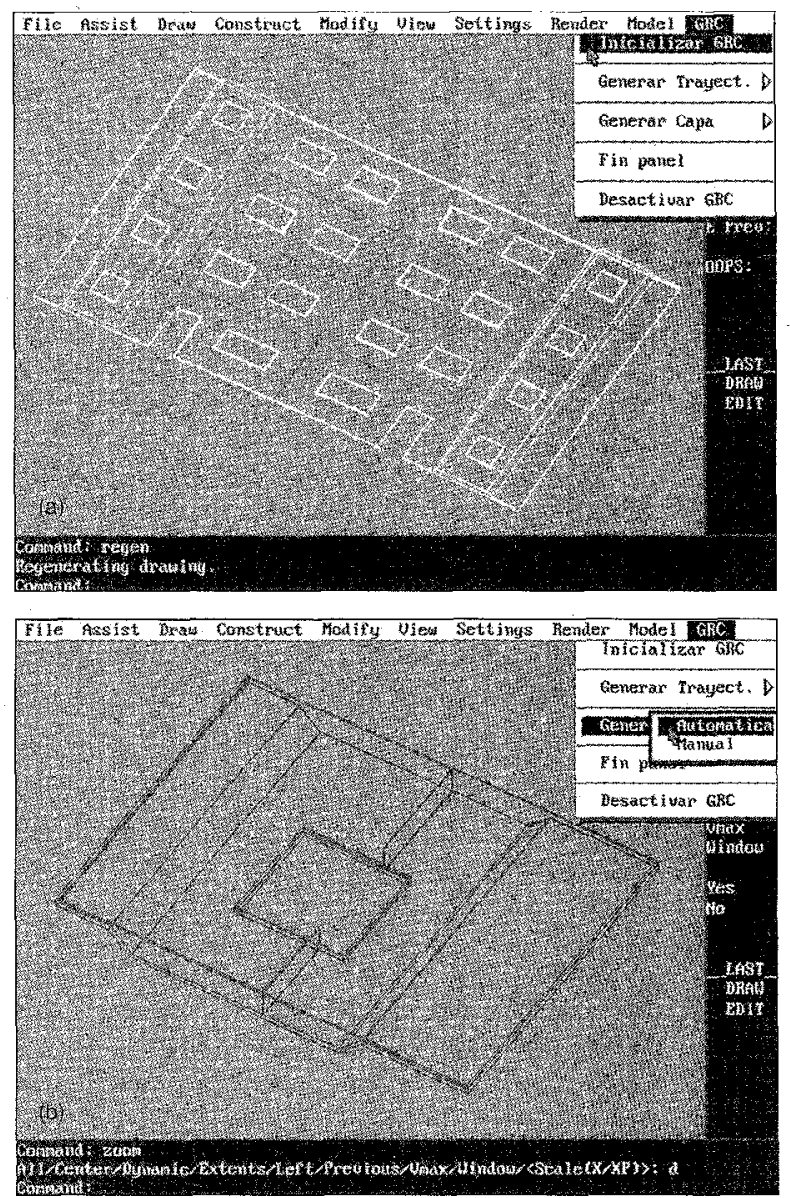

Figure 7. a) CAD $3 D$ facade drawing. b) Panel mold obtained by facade partition.

$$
D=\frac{A}{2} \frac{1}{\tan (\alpha / 2)}
$$

where $\mathrm{A}$ is the path width and $\alpha$ is the cone angle (Fig. 8a).

- Slopes in the bottom of the mold less than $7 \mathrm{~cm}$ are ignored in the generation of the spraying orientation (Fig. 8b).

- The linear spraying velocity is:

$$
\mathrm{V}=\frac{\mathrm{F}}{\mathrm{E} \times \mathrm{A}}
$$

where $\mathrm{F}$ is the mortar flow in $\mathrm{m}^{3} / \mathrm{s}$ and $\mathrm{E}$ is the layer thickness in $\mathrm{m}$. It is necessary to maintain the constant linear velocity $\mathrm{V}$ in order to obtain constant panel thickness.

- Bottom and sides of the mold are spraved in different stages.

- In order to reinforce the panels, corners, and edges, the amount of material sprayed in these zones must be greater than in other zones.
- The spraying of the bottom is done alternatively in perpendicular directions for consecutive layers (Fig. 8c).

- Spraying direction of the gun in the bottom is interpolated if the angle between bottom planes is more than $60^{\circ}$ (Fig. 8d).

\section{ROBOT PATH PLANNING}

\section{Robot Path Generation}

There are several steps in the automatic robot path planning algorithm. This algorithm receives data of the mold 3D drawing together with the spraying parameters and generates the real robot path and spraying gun commands (Fig. 9). This fig ure shows only the spraying of the mold bottom layer in one direction. In contrast the real panels have a minimum of two layers, vertical planes on edges, sometimes hollows for windows, etc. The path planning algorithm works initially with a spraying gun path only and then transforms it to a robot path [11]. From the mold data (Fig. 9a) a theoretical spraying gun path is calculated (Fig. 9b). The theoretical path consists of parallel straight line segments forming a grid over each automatically generated panel layer. It also includes orientations in the initial and final points of segments.

To ensure the homogeneity of the layer the paths are parallel straight lines segments on plane surfaces (curve surfaces are approximated by several planes). Therefore each straight line segment can be defined by its two extreme points. This information would be enough to specify the position in the mold where the center of the spraying cone base must be placed, but more information is needed to determine the orientation and the distance from the mold to the gun's tip.

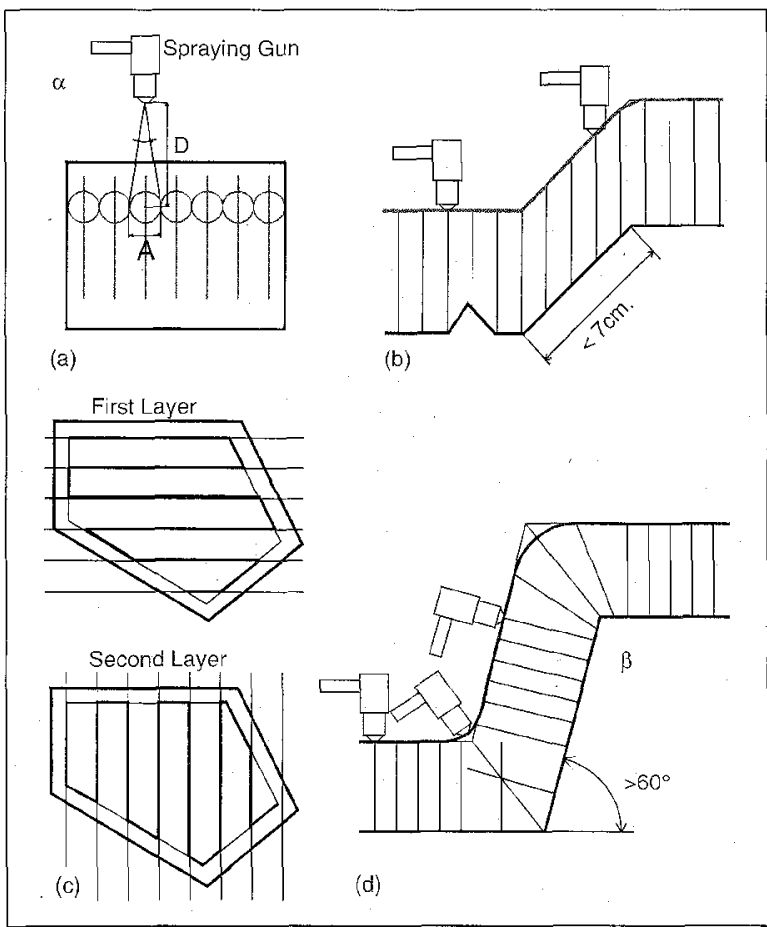

Figure 8. Spraying rules. 


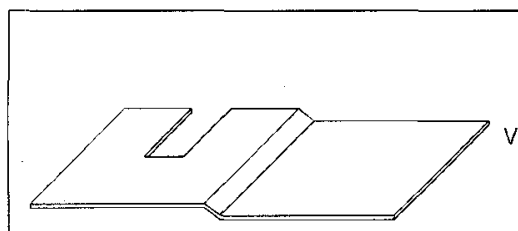

(a) Mold Drawing (Bottom)

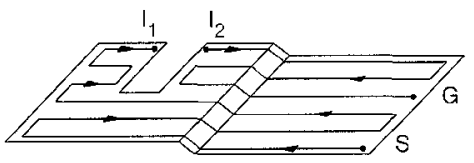

(c) Real Spraying Gun Path

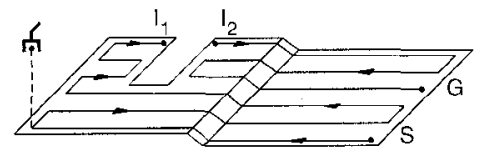

(e) Adapted Robot Path

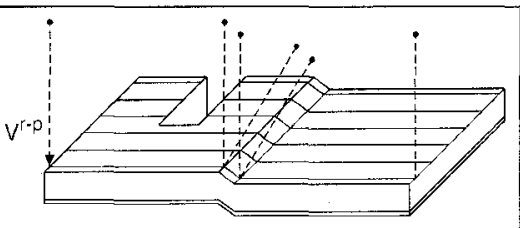

(b) Panels Layer and Theoretical Spraying Gun Path

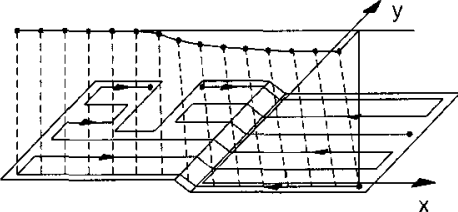

(d) Theoretical Robot Path

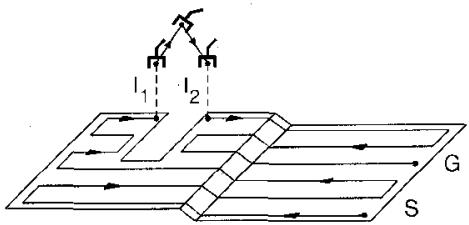

(f) Real Robot Path

Figure 9. Robot path planning steps.

Hence, for each point on the surface of the layer it is necessary to calculate another point indicating where the gun's tip is to be located. A vector called robot-to-panel vector $v^{r-p}$ (Fig. $9 \mathrm{~b})$ expresses the distance and orientation of the gun. It is important to note that in the intersection of two planes for each panel point there are two different gun tip positions, one perpendicular to each plane. Following the last spraying rule (Fig. 8d) the intermediate point between both is considered.

Once the straight segments needed to spray a whole panel have been generated, the objective is to obtain a real spraying gun path (Fig. 9c). The path starts in S and ends in G (both are automatically selected) and includes intermediate points $\left(\mathrm{I}_{1}\right.$ and $\left.\mathrm{I}_{2}\right)$ where the spraying has to be stopped and restarted. This step consists of calculating the optimum way to track the straight segments, considering the following restrictions in order to establish the best solution:

- Minimum number of gun stops: the robot can go from one segment to the next without stopping the gun. It can not spray the same segment twice or spray into the windows, etc. This is the most important condition of all.

- Minimum robot kinematics configuration changes: these changes are time consuming and require stopping the gun, withdrawing the robot from the panel, rotating one or more joints of the robot in order to change configuration, approaching the robot again and restarting the gun.

- Vertical progress of the path: the spraying must be done upwards in the slopes, especially on the sides of the panel (usually vertical ones).

All these restrictions, and a few more that were found on the prototype cell, are used to select the best feasible path with the help of an exhaustive graph search [12], [13]. The weights of each condition change dynamically according to panel specifications.

The resulting trajectory has a wavy pattern in order to obtain better uniformity. The theoretical study done in [14] supports our experimental results of minimal variation of the accumulated film thickness on the mold surface.

To obtain the theoretical robot path (Fig. $9 \mathrm{~d})$ a kinematics study of the generated real spraying gun path is performed. The straight segments are subdivided in equally spaced (about $10 \mathrm{~cm}$ ) spraying points for the robot. Moreover, to avoid singular robot positions several modifications of these points are made, e.g., changing the orientation of the gun in conflict areas and axes [15]. In Fig. $9 \mathrm{~d}$, to avoid movements in a singular area (along the positive part of axis $x$ with $y=0$ or close to them), the orientation of the robot has been modified without changing the spraying point on the mold. Other possible singularities are the movements close to the joints limit. Fig. 10 shows this situation, where the joint limit $\theta_{1}$ is avoided through modification of the gun orientation. There are some other singularities which have been taken in account.

\section{Kinematics Robot Path}

The objective is to position the robot with the appropriate orientation over the panel (Fig. 9e). This is the step where for the first time the robot kinernatics is analyzed. Because of the nature of the manufacturing process three additional restrictions, one static and two dynamic, have to be considered:

- The path must be continuous in orientation to avoid sudden changes in the orientation of the spraying gun with negative influence in the path quality.

- Due to the extreme fragility of the glass fiber that goes to the spraying gun along the arm of the robot, the angle of the last joint $\left(\theta_{6}\right)$ must always be in the range of $\pm 20^{\circ}$.

- In general, the robot must move following straight line segments in Cartesian coordinates. This implies the existence of multiple singular points which must be avoided.

To generate the kinematics robots path, several sequential steps are performed. First, to fulfill continuous orientation path restrictions, an algorithm to smooth the degree of change of the orientation is executed. The algorithm transforms each robot-to-panel vector $v_{i}^{r-p}$ into $v_{i}^{r-p}$ by means of the following equations (Fig. 11):

$$
\begin{aligned}
& \mathbf{v}_{\mathrm{i}}^{r^{\prime}-p}=\mathrm{p}-\mathrm{D} \frac{\boldsymbol{w}}{\|w\|} \\
& \boldsymbol{w}=\frac{\sum_{j=i-k}^{i+1} a_{j} \mathbf{v}_{j}^{r-p}}{\sum_{j=i k}^{i+1} a_{j}}(1, j>0)
\end{aligned}
$$

where $\mathbf{p}$ is the point on the panel, $\mathrm{D}$ is the spraying distance and $a_{j}, 1$ and $k$ indicate how the interpolation with preceding and following points is performed. This data has been obtained through factory tests and is fixed for each specified 
geometry, as shown in [6]. It is important to note that only the robot position is modified $\left(r^{\prime} \neq r\right)$, while the point $p$ on the panel remains the same. This transformation makes the path continuous in orientation.

The next step is the fulfillment of the glass fiber orientation restriction in Cartesian coordinate movements. The developed algorithm is an iterative one. Its basic idea is similar to [16] but is applied for multiple singularities and not for

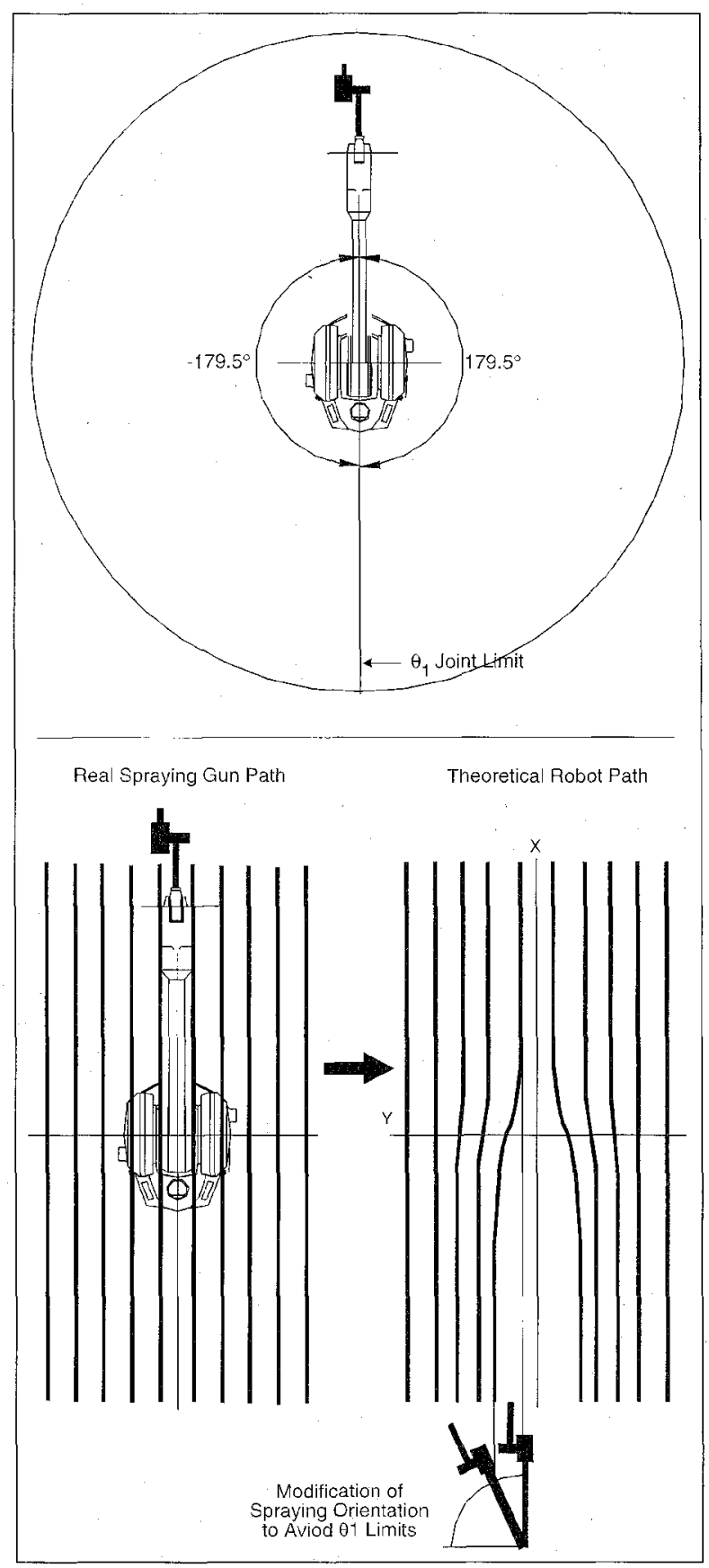

Figure 10. Joint limits avoidance through change in the orientation. an ordinary singularity. It is executed sequentially for each pair of points of the robot-to-panel vector $\boldsymbol{v}^{\prime}{ }^{\prime}$. A priori in order to place the robot in the desired point, only vector a from the $\{\mathbf{n}, \mathbf{0}, \mathbf{a}\}$ system is fixed, and coincides in direction. with the robot-to-panel vector $v^{r^{r}-p}$ (Fig. 12). To obtain an $\mathbf{n}$ vector that fulfills restriction on $\theta_{6}$, first an arbitrary value of $\mathbf{n}$ is chosen. Then through an iterative procedure (Fig. 13) that makes use of the inverse kinematics and a rotation around vector $\mathbf{a}$, a value of $\theta_{6}$ is adjusted to be very close to $0^{\circ}$. The process is performed with different elbow and wrist configurations, and the best solution considering orientation continuity is selected. This is very important because the robot will be commanded in Cartesian coordinates in order to move in straight line segments.

\section{Robot Approach and Retreat}

The final step in the path planning is the generation of a real robot path (Fig. 9f) through the use of robot approach and retreat algorithms. These algorithms move the robot to two distant points, avoiding collision with the mold. Examples of these paths are the approach path to the first spraying point, the retreat path from the last one and the connection path without spraying of two intermediate points (for example, points $\mathrm{I}_{1}$ and $\mathrm{I}_{2}$ of Fig. 9f).

The connection path between two intermediate points (in robot coordinates) without spraying can be subdivided in a retreat and an approach path that are symmetric (Fig. 14): retreat from point $O$ to point $R$ and then to point $R^{\prime}$, and approach from point $A^{\prime}$ to $A$ and then to point $D$. Both retreat and approach paths are obtained by applying the same algorithm in a direct or inverse way. In each step of the algorithm some values of the different axes are modified, while others remain fixed (Fig. 14).

Directing the robot to retreat from the mold can be accomplished in two different ways: a) following the spraying axis direction, vector a of the $\{\mathbf{n}, \mathbf{0}, \mathbf{a}\}$ system, and b) following an upstairs direction (Fig. 15). During this procedure it is very important to maintain low values of $\theta_{5}$ and $\theta_{6}$, and special care must be devoted to avoid sudden changes in the configuration.

The real robot path is the final result of the path planning and is saved in path files that are later used as source information for the on-line control. Simultaneously with the path planning and in direct relation to it, more specific informa-

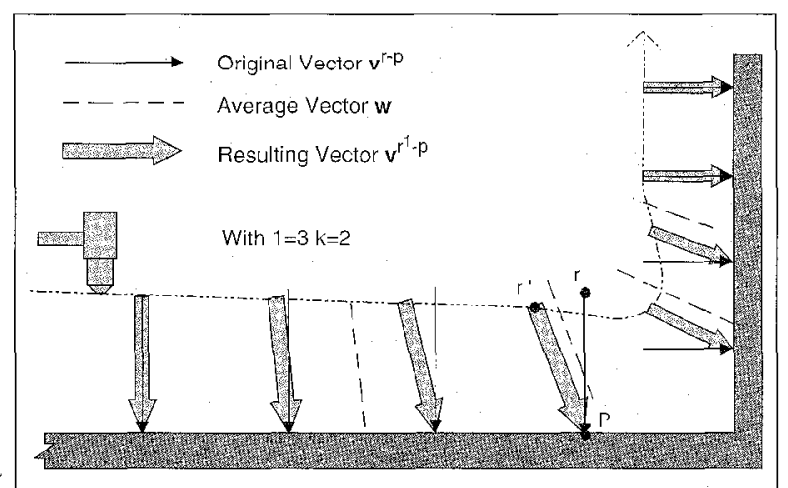

Figure 11. Algorithm to smooth the change in orientation. 


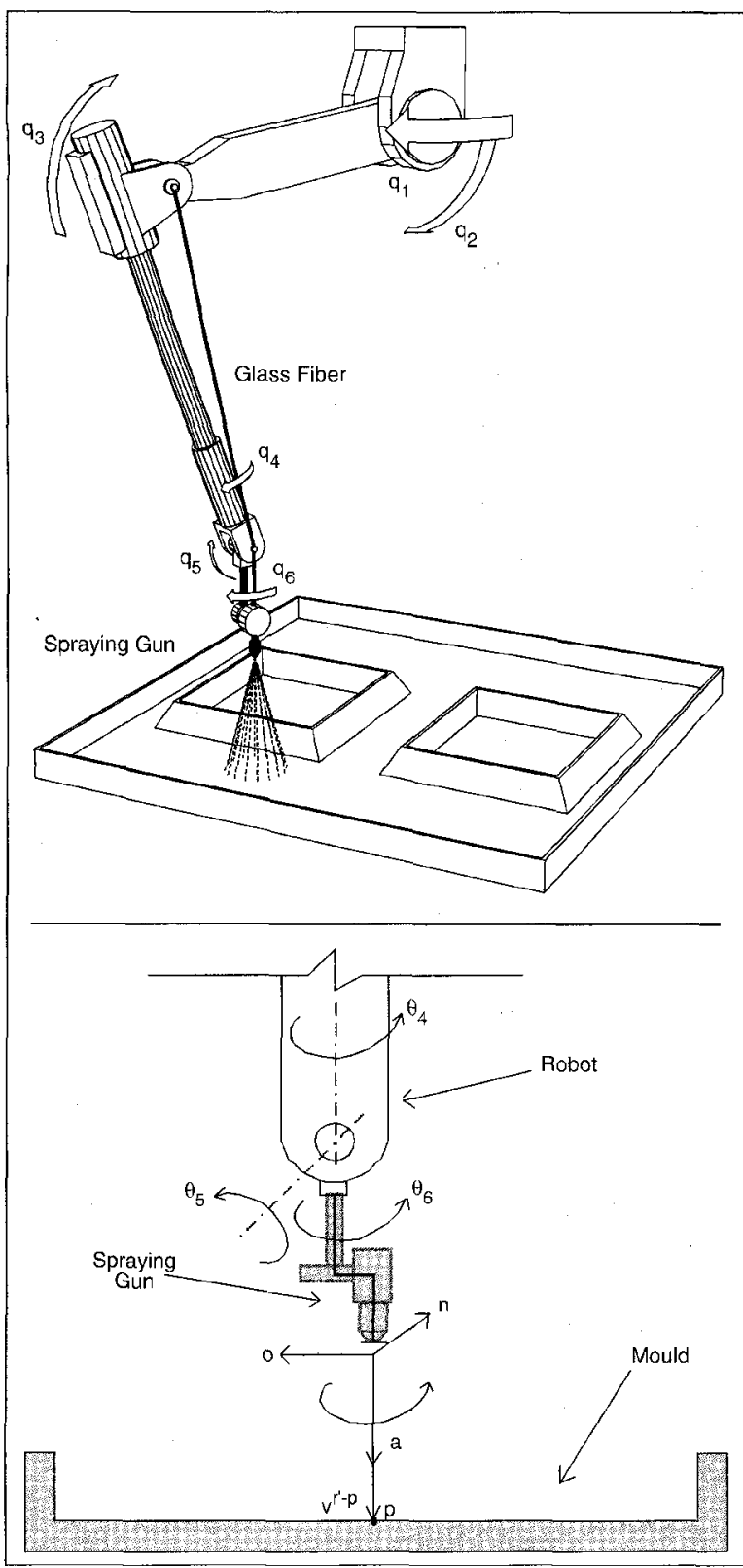

Figure 12. Glass fiber orientation restrictions.

tion is also generated: task sequences (which are stored in a specific task file), number and type of layers, positions where to stop/start gun, PLCs commands to be executed by the peripheral equipment, etc.

\section{ON-LINE CONTROL OF THE ROBOT CELL}

The path files that have been generated in the preceding stages are executed by the on-line control module. Four different processes run sequentially on the on-line computer: the scheduler, the robot control, the monitor of events and the man-machine interface.

The scheduler works as the core engine [17]. Reading task files and event information from the monitor, it decides which action to perform. In the case of robot commands, it transfers the control to the robot module and in the case of a command to the PLCs it issues the command itself. It makes its own decisions regarding events response. For example, suppose the continuous fiber strip is unexpectedly broken. A visual sensor notices the accident and transfers the information to the scheduler via the monitor. The scheduler stops the gun along with any other involved equipment and issues a command to the robot module to move the robot to the "fiber repair" position. Simultaneously it generates a message on the man-machine interface. The scheduler assumes standby status until through a push-button the resume command is received. Finally, the scheduler sends a resume command to the robot module, that restarts the gun spraying at the last point.

Since all the time-consuming computational work has already been done in the path planning stage, the robot control module is fairly simple. It reads the path files and sends the position commands to the robot controller through a dedicated serial link. These commands specify the position and orientation, type of coordinates and movement velocity. The status of the commands execution is received and taken in consideration. In special situations in which an unexpected path has to be generated (as explained with the broken fiber event) a simplified version of the connection control algorithm is used.

The monitor displays on the man-machine interface all the common events as well as any other unexpected event that may influence the manufacturing performance. Most events from the robot controller are managed by the robot control module, and only those affecting robot malfunction are passed to the monitor. Messages about plant status are sent directly from the sensors to the PLCs, and from these to the network board events registers. Here the monitor withdraws them. Depending on the kind of event, they are passed to the scheduler, the interface or both.

Fig. 16 shows the man-machine interface during on-line control of the cell. Different user friendly menus allow interaction with the cell: start, pause, resume or halt production. These commands are received by the monitor, which passes them to the scheduler to begin proper actions. The status of different components of the cell (molds, mixer, robot, conveyors, etc.) is displayed through color code. A message bar on the bottom part of the screen shows any useful information about the processes evolution. In manual operation, the operator can act as the scheduler and issue to the cell whatever command he wishes. In maintenance operation complete information from the equipment state can also be requested.

\section{EVALUATION AND COMPARATIVE STUDY}

To evaluate the achieved improvements, the developed robotized system is compared to traditional manual manufacturing. The comparative study is based on two key factors: product quality and overall productivity [18].

The main criteria for product quality evaluation are uniformity of layers and structural parameters. The layers sprayed by the robot are more uniform than the layers obtained by manual spraying, primarily because the robot describes straight line paths in a specific direction over the entire sur- 


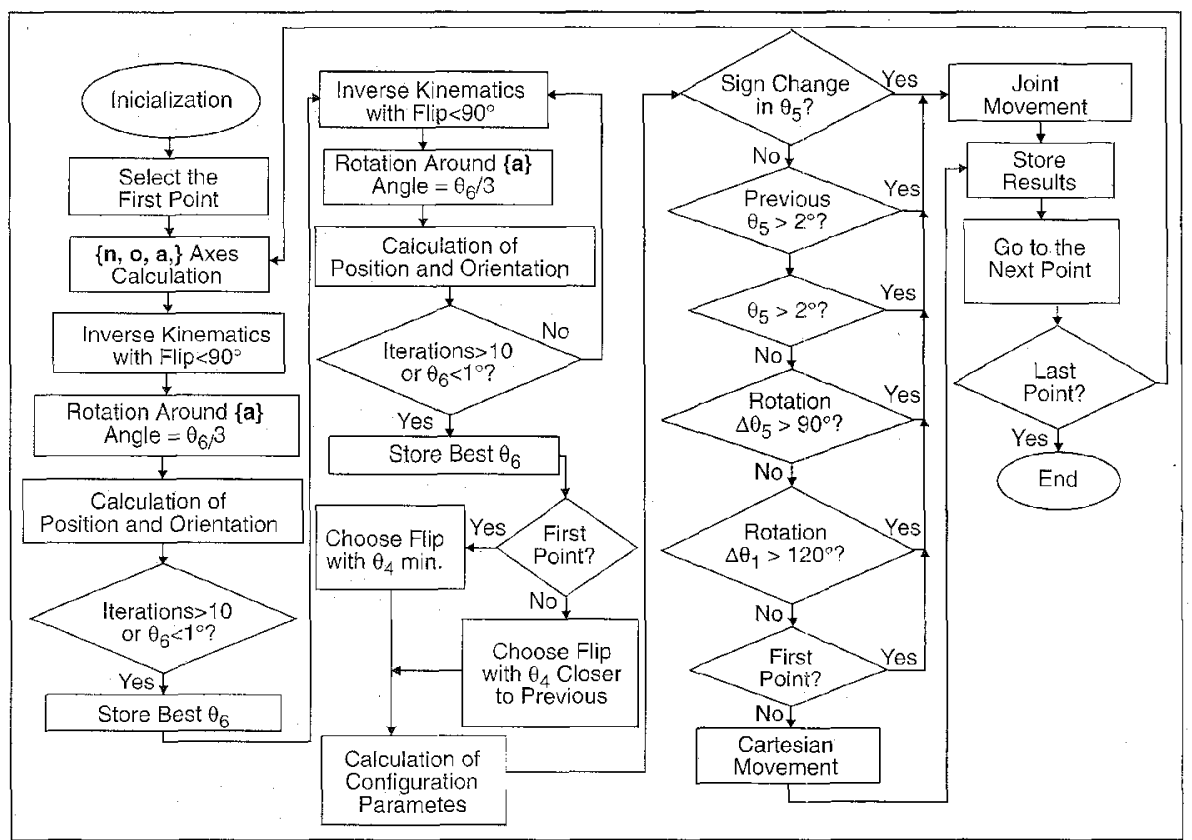

Figure 13. Flow diagram of the $\theta_{6}$ restriction algorithm.

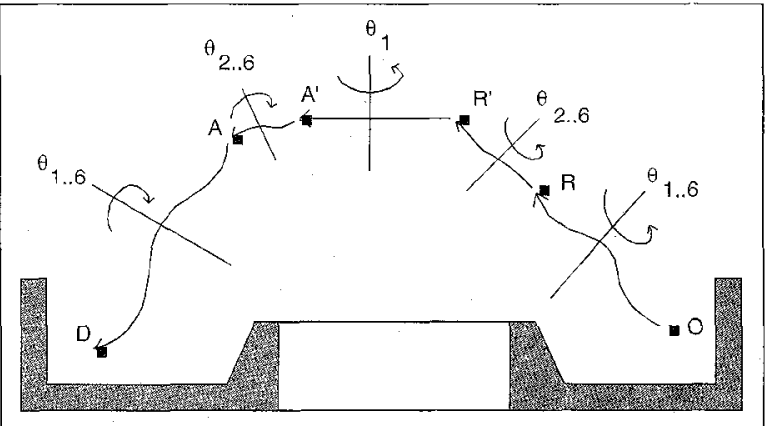

Figure 14. Retreat and approach paths.

face of the mold. The manually sprayed panel is more irregular, mainly because the reach of the worker is not large enough to encompass all the panel area, which has an average of $5 \times 3 \mathrm{~m}$. This it makes impossible to spray each segment without stopping the gun. Moreover, it is difficult to maintain the gun perpendicular to the mold surface. The robot also sprays with more uniformity due to greater pressure of the spraying gun. The pressure is more than the double that of the manual gun, accomplishing a and manual manufacturing. $\mathrm{PC}$-type computer. better mixing and compacting of the glass fiber with the mortar. This fact is very important, because it allows elimination of all intermediate compacting between layers, saving time and labor.

Thickness uniformity is also an important quality factor. It has a direct influence on the panel weight per $\mathrm{m}^{2}$. The ideal layer thickness is around $10 \mathrm{~mm}$ and no panel should have a thickness less than specified. In robotic spraying the thickness can be controlled by adjusting the robot linear velocity. This results in an average thickness very close to the ideal and a significant saving of material. Fig. 17 shows the manufacturing spraying parameters together with the comparison of a cross-section of robotized and manual spraying panels.

Mechanical structural features are also important for the quality evaluation of GRC panel manufacturing. The uniformity of spraying by robot can also be observed on flex-traction tests results. The strength of the test piece measured in longitudinal and transversal directions is very similar for robotized

The panel manufacturing time cycle can be divided into two different phases: a) mold design and drawing followed by path planning; and b) manufacturing in factory. The first phase, which is performed completely off-line, can be done in the technical office. If there are several panels with similar geometry they can be grouped together and successive panels can be generated quickly with slight modifications to the first one, taking an average of 20 min. per panel using a low-cost

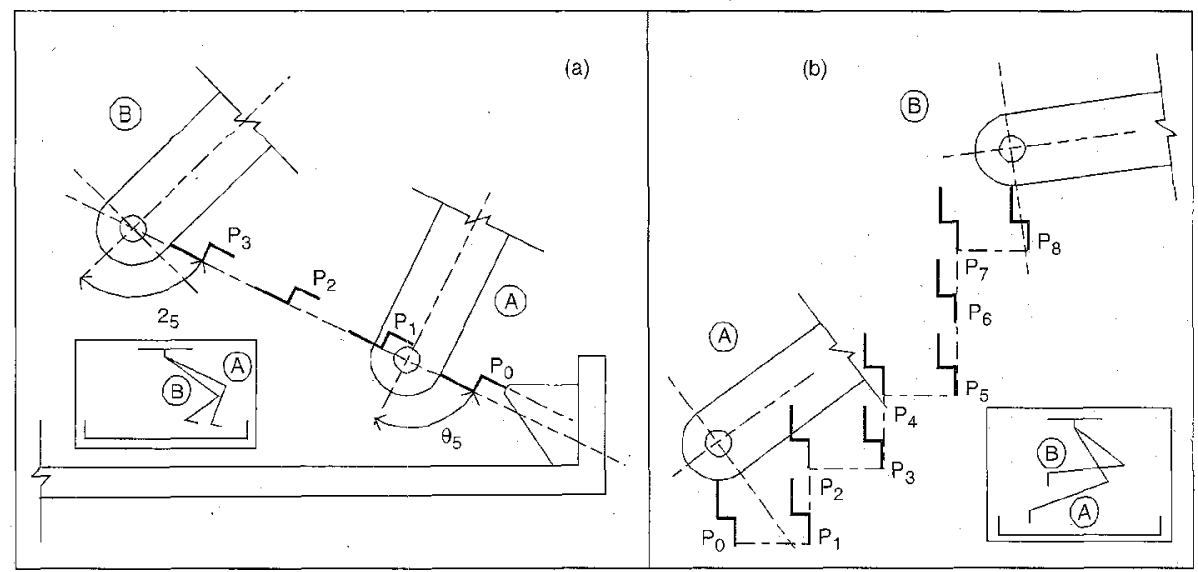

Figure 15. Directions of the retreat paths. a) Moving along the spraying axis. b) Moving upstairs. 


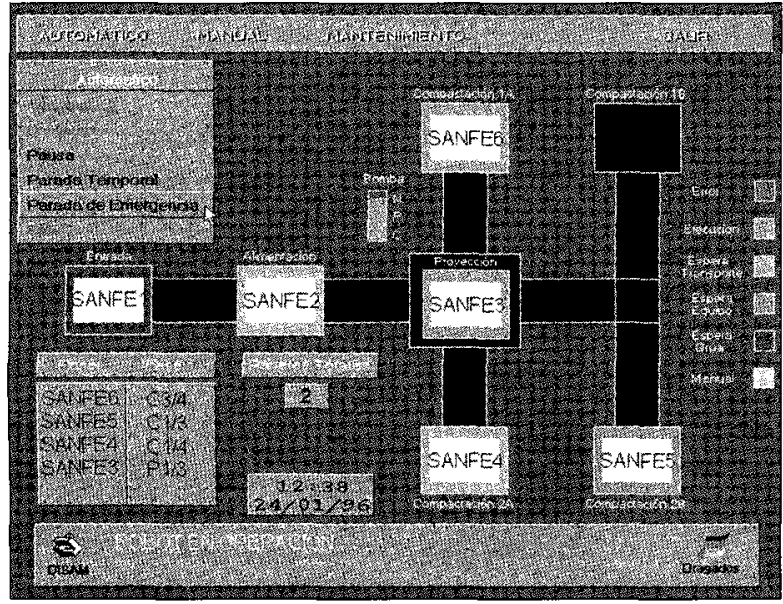

Figure 16. Man-machine interface.

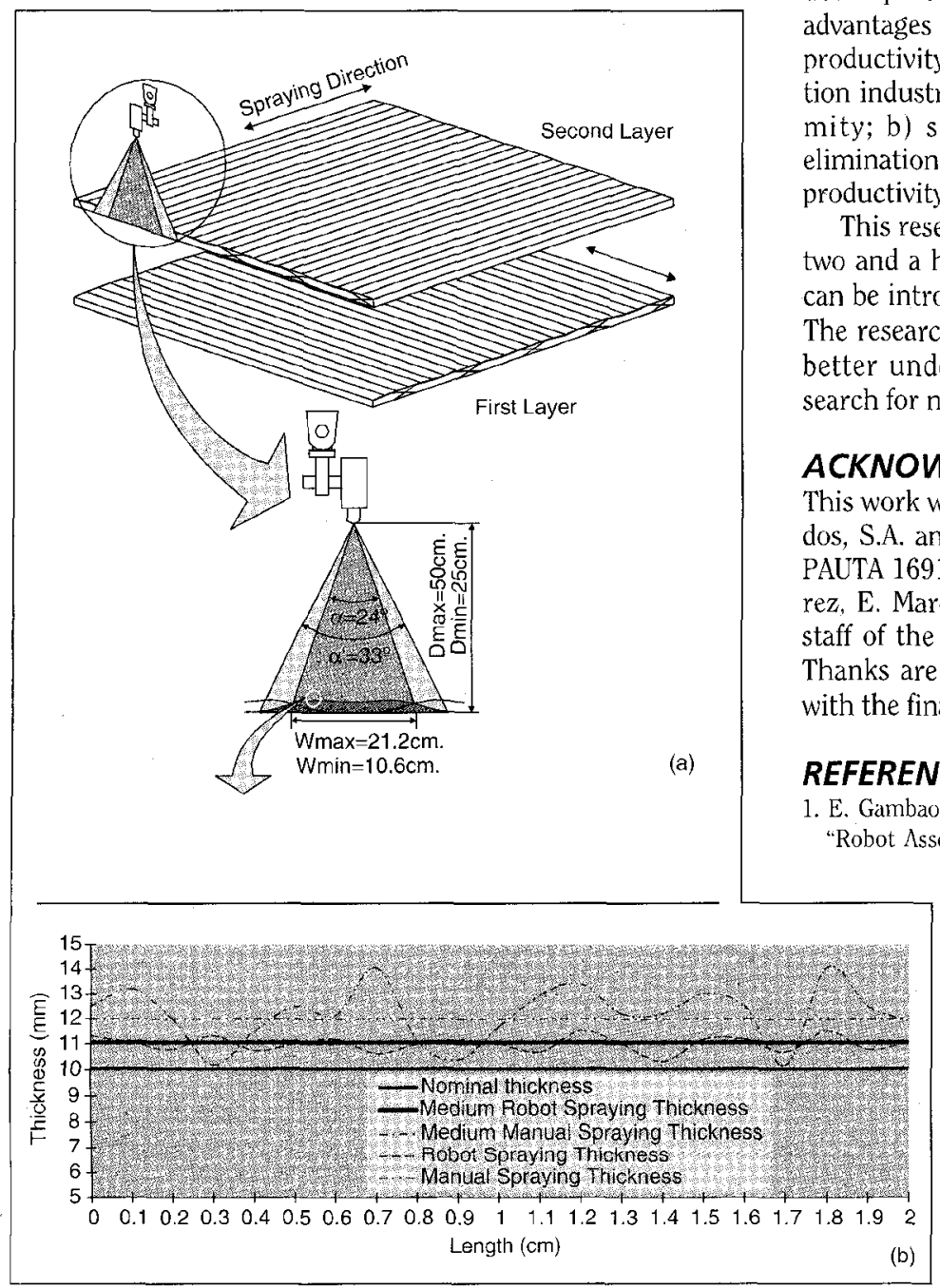

Figure 17. a) Manufacturing parameters. b) Cross section of robotized and manual manufacturing.
On the other hand, the robot spraying times are slightly less than the manual ones because the robot is spraying with a $28 \mathrm{~kg} / \mathrm{min}$ gun versus a $12 \mathrm{~kg} / \mathrm{min}$ manual gun. Therefore, the robot gun may move faster to maintain equal thickness, although there are certain dead times in changing from one point to another. The huge advantage of robotic spraying is the elimination of intermediate compacting between layers, as the mortar is sprayed with higher pressure and uniformity. This also eliminates transportation times together with robot idle stages, increasing significantly the whole productivity of the entire process for each panel. Fig. 18 shows the average spraying and manufacturing (which includes compacting) times for each function of the panel area. The results point to an important increase of productivity using the developed system.

\section{CONCLUSIONS}

The developed system (Fig. 19) presents a new step towards fully automatic manufacturing of prefabricated materials. The development of this system has shown some of the great advantages that automation can bring to quality and factory productivity in an off-site manufacturing process of construction industry: a) improvement in layers and thickness unifority; b) similar mechanical strength test results; c roductivity increase; and e) materials saving.

This research project has had a total duration of more than two and a half years. It proves that new robotic technologies can be introduced in construction industry with good results. research done during this time has also contributed to a better understanding of the production process and to a arch for new ways of automation.

\section{ACKNOWLEDGMENTS} the Spanish Ministry of Industry under project Marquez, C. Corpas, J. Arauzo and A. Cases, and the Caracola factory in Torrejón de Ardoz (Madrid). ks are also due to Christian Schäfer for his assistance the final manuscript.

\section{REFENCES}

C. Balaguer, A. Barrientos, R. Sallarén, and EA. Puente, obot Assembly System for the Construction Process Automation." IEEE International Conference on Robotics \& Automation. Albuquercue (USA), 1997.

2. H.-B. Kuntze, U. Hirsch, A. Jucabasch, F. Eberle, and B. Göller, "On the dynamic control of a hydraulic large range robot for construction applications." Automation in Construction, Vol. 4, No.1, 1995.

3. C. Balaguer, F.J. Rodríguez, J.M. Pastor, and L.F. Peñin, "Robotized system of GRC panels for construction industry." 10th International Symposium on Automation and Robotics in Construction (ISARC'93), Houston (USA), 1993.

4. U. Rembold, B.O. Nhaji, and A. Storr, Computer Integrated Manufacturing and Engineering. AddisonWesley, 1993.

5. Y. Yamazaki, "Conceptual design and construction planning system for Computer Integrated Construc- 


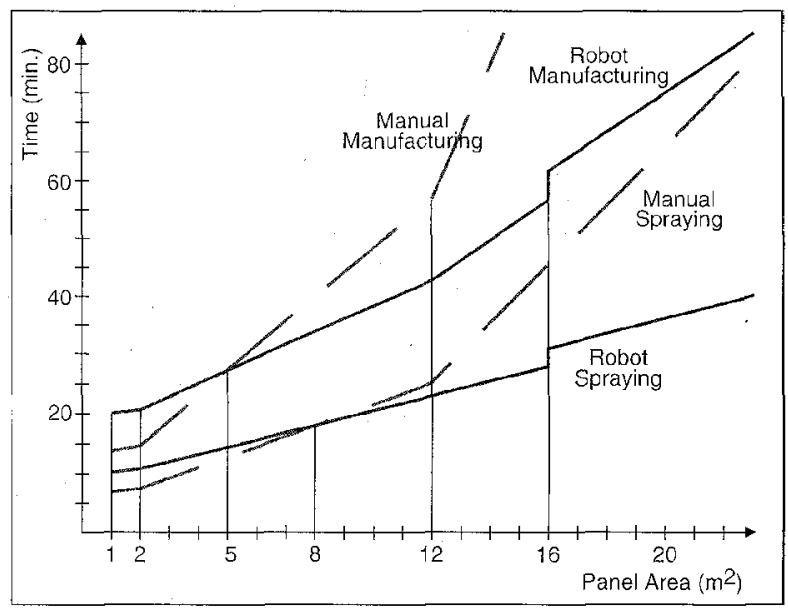

Figure 18. Comparison of robotized and manual productivity.

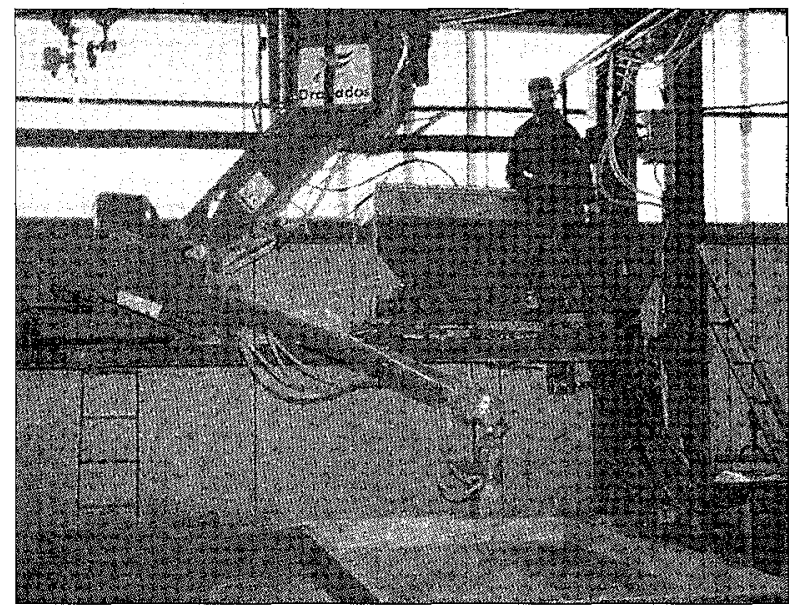

Figure 19. Developed system.

tion." Automation in Construction, Vol. 1, No. 1, 1992.

6. L.F. Peñin, J.M. Pastor, and C. Balaguer, "Automated production of non-standard facade panels and robot path planning for GRC spraying cell." 10th Congress of the International GRC Association, Strasbourg (France), 1995.

7. A. Viswanathan, M. Jouaneh. P. Datseris, and W. Palm, W., "A manufacturing system for automated production of polystyrene molds." IEEE Robotics \& Automation Magazine, Vol. 3, No. 3, 1996.

8. I.M. Pastor, L.F. Peñin, and C. Balaguer, "New approach to low-cost FMS for wide range of manufacturing applications." 2nd IFAC/IFIP/IFORS Workshop on Intelligent Manufacturing Systems (IMS94), Vienna (Austria), 1994

9. H.H. Cheng and R. Penkar, "Stacking irregular-sized packages by a robot manipulator." IEEE Robotics \& Automation Magazine, Vol. 2, No. 4, 1995

10. E.D. Goodman and L.T.W. Hoppensteadt, "A method for accurate simulation of robotic spray application using empirical parametrization.' IEEE International Conference on Robotics and Automation, (ICRA 91), Sacramento (USA), 1991.

11. C. Balaguer, J.M. Pastor, L.F. Peñin, and F.J. Rodriguez, "Automatic robot path planning for GRC spraying cell." 11th International Sym posium on Automation and Robotics in Construction (ISARC'94), Brighton (UK), 1994.

12. N. Christofides, "Graph theory. An algorithmic approach." Academic Press, 1975.
13. A. Hansen and F. Arbab, "An algorithm for generating NC tool paths for arbitrary shaped pockets with islands." ACM Transactions on Graphics, Vol. 11, No. 2, 1992.

14. J.K. Antonio, "Optimal trajectory planning for spray coating." IEEE International Conference on Robotics and Automation (ICRA'94), 1994

15. L.J. Everett, J.C. Colson, and B.W. Mooring, "Automatic singularity avoidance using joint variations in robot task modification." $I E E E$ Robotics \& Automalion Magazine, Vol. 1, No. 3, 1994.

16. J. Keiffer. "Manipulator inverse kinematics for untimed end-effector trajectories with ordinary singularities." The International Joumal of Robotics Research, Vol. 11, No. 3, 1992.

17. T.-H. Sun, C.-W. Cheng, and $\mathrm{L}_{-}-\mathrm{C} \mathrm{Fu}$, "A petri net based approach to modeling and scheduling for FMS and a case study." IEEE Transactions on Industrial Electronics, Vol. 41, No. 6, 1994.

18. C. Balaguer, A. García, J.M. Pastor, and L.F. Peñin, "Evaluation and comparative study of robotics vs manual spraying of GRC panels." 12th International Symposium on Automation and Robotics in Construction (ISARC'95), Warsaw (Poland), 1995.

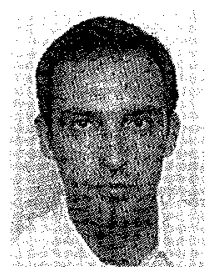

Luis F. Peñin was born in Madrid, Spain. He received a B.S. in Electronics and Control Engineering and an M.S. in Control Engineering in 1993, both from the Universidad Politécnica de Madrid (UPM). Ile received his Ph.D. in Robotics from the UPM in 1998. He has published several papers and a book in the field of robotics; has also participated in various industrial projects in robotics and automation as well as in the development of a teleoperation system. He will join the National Aerospace Laboratory (NAL) of Japan in 1998. His current research interests lie in the area of service robots, telerobotics, bilateral control, and haptic interfaces.

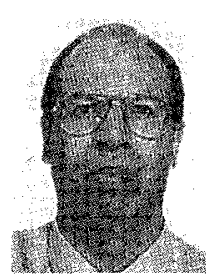

Carlos Balaguer is Full Professor of System Engineering and Automation at the Carlos III University of Madrid, Spain. He received the Ph.D. degree in Robotics from the Polytechnic University of Madrid, Spain, in 1983. Prof. Balaguer is a member of the IEEE and other international science associations and has published over 80 papers and books in the field of robotics. He has participated in numerous national and international R\&D projects in robotics and automation. His current research interests concern the development and control of service robots (manipulators, mobile robots, mobile manipulators, self-supported robots, etc.) for the construction, aeronautic, and electrical sectors as well as other industries.

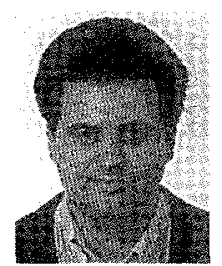

José M. Pastor was born in León, Spain. He received the Electronics and Automatic Control Engineering degree from the Poly technic University of Madrid (UPM) in 1991. In 1992 he began his doctoral research in Robotics in Construction Industry. From 1994 to 1995 he was a teaching assistant in the Electrical Department of the Open University of Spain. In 1995 Dr. Pastor moved to the Engineering Department of the Carlos III Uni 
versity of Madrid where he is currently an Assistant Professor. He received his Ph.D. in Robotics in 1997 from the UPM. His research interests include intelligent manufacturing systems, service robot applications, robot path planning, and collision avoidance.

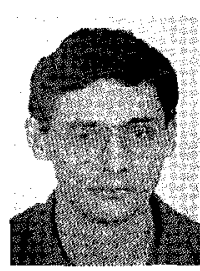

Francisco J. Rodríguez is Associate Professor of System Engineering and Automation at the University Carlos III of Madrid, Spain. He received the Ph.D. degree in Artificial Intelligence and Robotics from the Polytechnic Lniversity of Madrid, Spain, in 1993. His current research interests concern the control of special purpose robots, computational problems in robotics and robot collision avoidance planning. Recently he has also worked in the field of Computer Integrated Manufacturing and Flexible Manufacturing Systems.

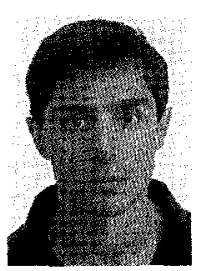

Antonio Barrientos received his Control Engineering degree and Ph.D. in Robotics from the Universidad Politécnica de Madrid (UPM) in 1982 and 1986, respectively. He began working as a researcher in the System Engineering and Automation Division (DISAM) of the UPM, where he became Associate Professor in 1988. Now he is responsible of the DISAMs Robotics Group. He has participated in various projects in robotics and telerobotics. Dr. Barrientos has published numerous papers in conferences and technical journals and also several books in the field of robotics and processes control.

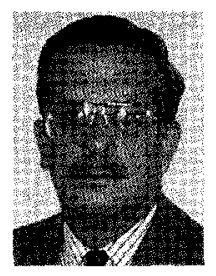

Rafael Aracil was born in Alcoy, Spain. He received the Electrical Engineer and $\mathrm{Ph} . \mathrm{D}$. in Engineering from the Polytechnic University of Madrid in 1971 and 1975, respectively. Since 1973 he has been with the System Engineering and Automation Division (DISAM) of the Polytechnic University of Madrid, becoming Full Professor in 1983. His main research interests are robotics, computer vision for automation and image processing. He is currently creating a robotics research institute in the Lniversidad Miguel Hernández of Elche.

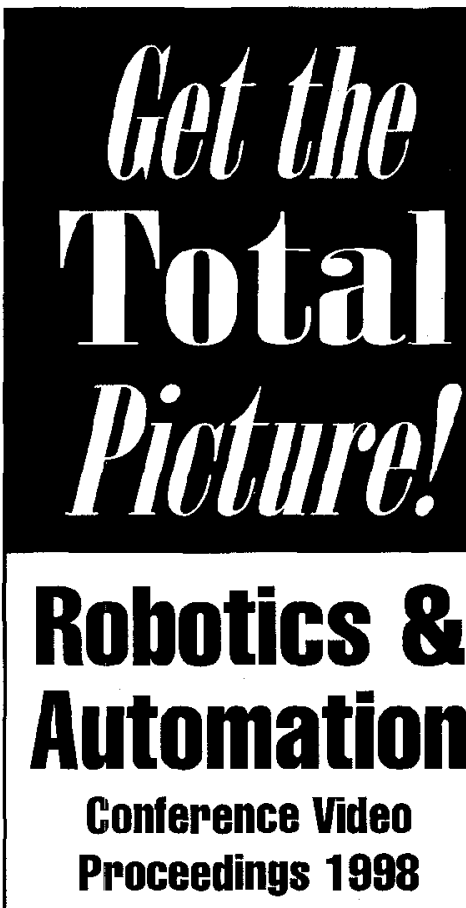

sponsored by the

IEEE Robotics and Automation Sociely and IEEE Educational Activities

The tradition continues. ICRA ' 98 brings you this year's Conference Video Proceedings on new experimental restilts, demonstrations, and induslrial case studies in robotics and automation Video Proceedings

further enhance and complement results presented in technical sessions and published in CD-ROMS. Video Proceedings ' 98

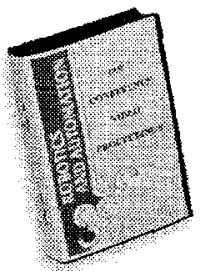

Previous years' REA Conference Video Proceedings are still available - see bttp://wwwieee.org/eab for information!

includes 27 segments broken down into the following groups: Teleoperation, Rehabilitation Robotics, Humanoid Robots, Robots in Games, Mobile Robots, Manufacturing Automation, Maripulation and Control, and Robotic Subsystems.

May 1998

Approx. 1 Hour 15 Min./1 Videolape List Price: $\$ 130.00$ • Member Price: $\$ 85.00$ NTSC Product No. HV7019-0SP

NTSC ISBN 0-7803-4580-0

PAL Product No. HV7020-QSP

PAL ISEN 0-7803-4581-9

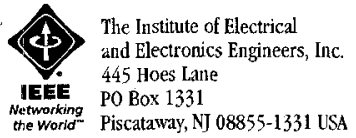

Visit the IEEE Educational Activities Home Page: http://www, ieee.org/eab

Order 24 Hours a Day, 7 Days a Week! Phone 1 (800) 678-IEEE

(Toll-Free USA and Canada)

or 1 (732) 981-0060, Fax 1 (732) 981-9667 E-Mail customer-service@ieec.org 